OPEN ACCESS

Edited by:

Andrea Guzzetta,

University of Pisa, Italy

Reviewed by:

Mary Ann Rutherford,

King's College London,

United Kingdom

Rob Forsyth,

Newcastle University, United Kingdom

*Correspondence:

Kate Himmelmann

kate.himmelmann@vgregion.se

Specialty section:

This article was submitted to

Pediatric Neurology,

a section of the journal

Frontiers in Neurology

Received: 15 October 2020 Accepted: 17 December 2020 Published: 03 February 2021

Citation: Himmelmann K, Horber V, Sellier E,

De la Cruz J, Papavasiliou A, Krägeloh-Mann I and the Surveillance of Cerebral Palsy in Europe (SCPE) Collaboration (2021) Neuroimaging Patterns and Function in Cerebral

Palsy-Application of an MRI Classification

Front. Neurol. 11:617740 doi: 10.3389/fneur.2020.617740

\section{Neuroimaging Patterns and Function in Cerebral Palsy-Application of an MRI Classification}

\author{
Kate Himmelmann ${ }^{1 *}$, Veronka Horber ${ }^{2}$, Elodie Sellier ${ }^{3,4}$, Javier De la Cruz ${ }^{5}$, \\ Antigone Papavasiliou ${ }^{6}$, Ingeborg Krägeloh-Mann ${ }^{2}$ and \\ the Surveillance of Cerebral Palsy in Europe (SCPE) Collaboration
}

${ }^{1}$ Department of Pediatrics, Clinical Sciences, Sahlgrenska Academy, University of Gothenburg, Gothenburg, Sweden, ${ }^{2}$ Department of Paediatric Neurology, University Children's Hospital, Tübingen, Germany, ${ }^{3}$ Univ. Grenoble Alpes, CNRS, Grenoble INP, CHU Grenoble Alpes, TIMC-IMAG, Grenoble, France, ${ }^{4}$ RHEOP, Grenoble, France, ${ }^{5}$ Research Institute (i+12), SAMID, University Hospital "12 Octubre", Madrid, Spain, ${ }^{6}$ Department of Paediatric Neurology, IASO Children's Hospital, Athens, Greece

Background: Cerebral palsy (CP) is a disorder of movement and posture and every child with $\mathrm{CP}$ has a unique composition of neurological symptoms, motor severity, and associated impairments, constituting the functional profile. Although not part of the $\mathrm{CP}$ definition, magnetic resonance imaging (MRI) sheds light on the localization, nature, and severity of brain compromise. The MRI classification system (MRICS), developed by the Surveillance of Cerebral Palsy in Europe (SCPE), describes typical MRI patterns associated with specific timing of vulnerability in different areas of the brain. The classification has proven to be reliable and easy to use.

Aims: The aim of this study is to apply the MRICS on a large dataset and describe the functional profile associated with the different MRI patterns of the MRICS.

Materials and Methods: Data on children with CP born in 1999-2009 with a post-neonatal MRI from 20 European registers in the JRC-SCPE Central Registry was included. The CP classification and the MRICS was applied, and The Gross Motor Function Classification (GMFCS) and the Bimanual Fine Motor Function (BFMF) classification were used. The following associated impairments were documented: intellectual impairment, active epilepsy, visual impairment, and hearing impairment. An impairment index was used to characterize severity of impairment load.

Results: The study included 3,818 children with post-neonatal MRI. Distribution of CP type, motor, and associated impairments differed by neuroimaging patterns. Functional profiles associated with neuroimaging patterns were described, and the impairment index showed that bilateral findings were associated with a more severe outcome both regarding motor impairment and associated impairments than unilateral compromise. The results from this study, particularly the differences in functional severity regarding uni- and bilateral brain compromise, may support counseling and service planning of support of children with CP.

Keywords: cerebral palsy, neuroimaging, MRI pattern, associated impairments, functional profile, impairment index 


\section{INTRODUCTION}

Cerebral palsy (CP) is defined as a disorder of movement and posture affecting activity. In the latest definition, accompanying impairments are acknowledged (1). Every child with CP has a unique composition of neurological symptoms, motor severity, and accompanying impairments, constituting their functional profile. National guidelines have long recommended magnetic resonance imaging (MRI) as a diagnostic step after history taking neurological examination and examination of additional impairments (2). International guidelines also view MRI as part of the work-up (3). Although not part of the CP definition, MRI sheds light on the localization, nature, and extent of brain compromise. Whether the lesions affect cerebral hemispheres uni- or bilaterally will affect the capacity for plasticity and ultimately the outcome, and insults to core structures important for network building are also of importance (4). Typical MRI patterns have been identified and associated with specific timing of vulnerability in different localizations of the brain $(5,6)$. Several classifications of MRI findings in CP have been proposed (7-10). One is the MRI classification system (MRICS), developed by the Surveillance of Cerebral Palsy in Europe, SCPE $(11,12)$. A first report of European population-based results of the MRICS was recently published (13). The quality of the MRICS data relies on training of the register partners, who, guided by the Reference and Training Manual and annual exchange and discussions, do the classification of MRI reports and scans and are instructed to classify the neuroimaging pattern which most likely is the cause of the CP. Classifications done are validated by three pediatric neurologists with specific expertise in MRI (IK-M, VH, and $\mathrm{KH}$ ). This classification has been proved to be reliable and easy to use in this way (12).

The structure-function relationship with regard to neuroimaging findings and $\mathrm{CP}$ has previously been addressed by the SCPE in the Reference and Training Manual ${ }^{1}$ (14) and in a previous study (13), where the distribution of MRI patterns was reported by different gestational ages and CP subtypes.

Following this path, the aim of the present study was to apply the MRICS on a large population-based dataset and describe the functional profiles found, by the different MRI patterns of the MRICS. A second aim was to compare the outcome with respect to uni- and bilateral MRI findings.

\section{MATERIALS AND METHODS}

\section{Study Population}

Data were gathered from 20 geographically defined case registers across Europe. Children with CP born between 1999 and 2009 were included if they fulfilled clinical criteria after their 4th birthday. Children whose brain damage occurred after the neonatal period (beyond the 28th day after birth) were excluded.

\footnotetext{
Abbreviations: BFMF, Bimanual Fine Motor Function; BSCP, bilateral spastic cerebral palsy; CP, cerebral palsy; GMFCS, Gross Motor Function Classification System; MRI, magnetic resonance imaging; USCP, unilateral spastic cerebral palsy. ${ }^{1}$ https://eu-rd-platform.jrc.ec.europa.eu/scpe/reference-and-trainingmanual_en (accessed October 14, 2020)
}

Children with a report of MRI performed after 1 month of age were then included.

\section{Data Collection}

The MRI classification (MRICS) of the SCPE was applied [Table 1; (12)]. The CP subtype was classified according to SCPE (11) into unilateral spastic CP (USCP), bilateral spastic CP (BSCP), dyskinetic CP, ataxic CP, or unknown. Gross motor function was classified according to the Gross Motor Function Classification (GMFCS) (15) and fine motor function according to the Bimanual Fine Motor Function (BFMF) classification (16, 17). Accompanying impairments were documented: Severe intellectual impairment was defined as an IQ below 50, tested or clinically estimated. Active epilepsy was defined as ongoing anti-epileptic medication. Severe visual impairment was defined as an acuity below 0.1 in the best eye, and severe hearing impairment was defined as hearing loss $>70 \mathrm{~dB}$ on the better ear, before correction.

The recently suggested impairment index (18) was applied when uni- and bilateral neuroimaging patterns were compared: Low impairment was defined as being able to walk (GMFCS I-II), IQ $\geq 70$, no visual impairment, no hearing impairment, and no epilepsy. High impairment was defined as inability to walk (GMFCS IV-V) and/or severe intellectual impairment (IQ <50), with or without one or more of the following impairments: severe visual impairment, severe hearing impairment, and active epilepsy. Moderate impairment included all other levels of impairment not defined as low or high [GMFCS I-II, IQ $\geq 70$, but with one or more of the following impairments: severe visual impairment, severe hearing impairment, active epilepsy, OR GMFCS I-II with an IQ $\geq 50$ and $<70$, with or without one or more of severe

TABLE 1 | The MRI classification system (12).

\section{A. Maldevelopments}

A.1. disorders of cortical formation (proliferation and/or migration and/or organization)

A.2. other maldevelopments (examples: holoprosencephaly. Dandy Walker malformation, corpus callosum agenesis, cerebellar hypoplasia)

\section{B. Predominant white matter injury}

B.1. periventricular leucomalacia, PVL (mild/severe)

B.2. sequelae of intraventricular hemorrhage (IVH) or periventricular hemorrhagic infarction (PVHI)

B.3. combination of PVL and IVH sequelae

\section{Predominant gray matter injury}

C.1. basal ganglia/thalamus lesions (mild/moderate/severe)

C.2. cortico subcortical lesions only (watershed lesions in parasagittal distribution/multicystic encephalomalacia) not covered under C3

C.3. arterial infarctions (middle cerebral artery/other)

\section{Miscellaneous}

(examples: cerebellar atrophy, cerebral atrophy, delayed myelination, ventriculomegaly not covered under $\mathrm{B}$, hemorrhage not covered under $\mathrm{B}$, brainstem lesions, calcifications)

\section{E. Normal}

Printed with permission. $\mathrm{NH}$, intraventricular hemorrhage. 


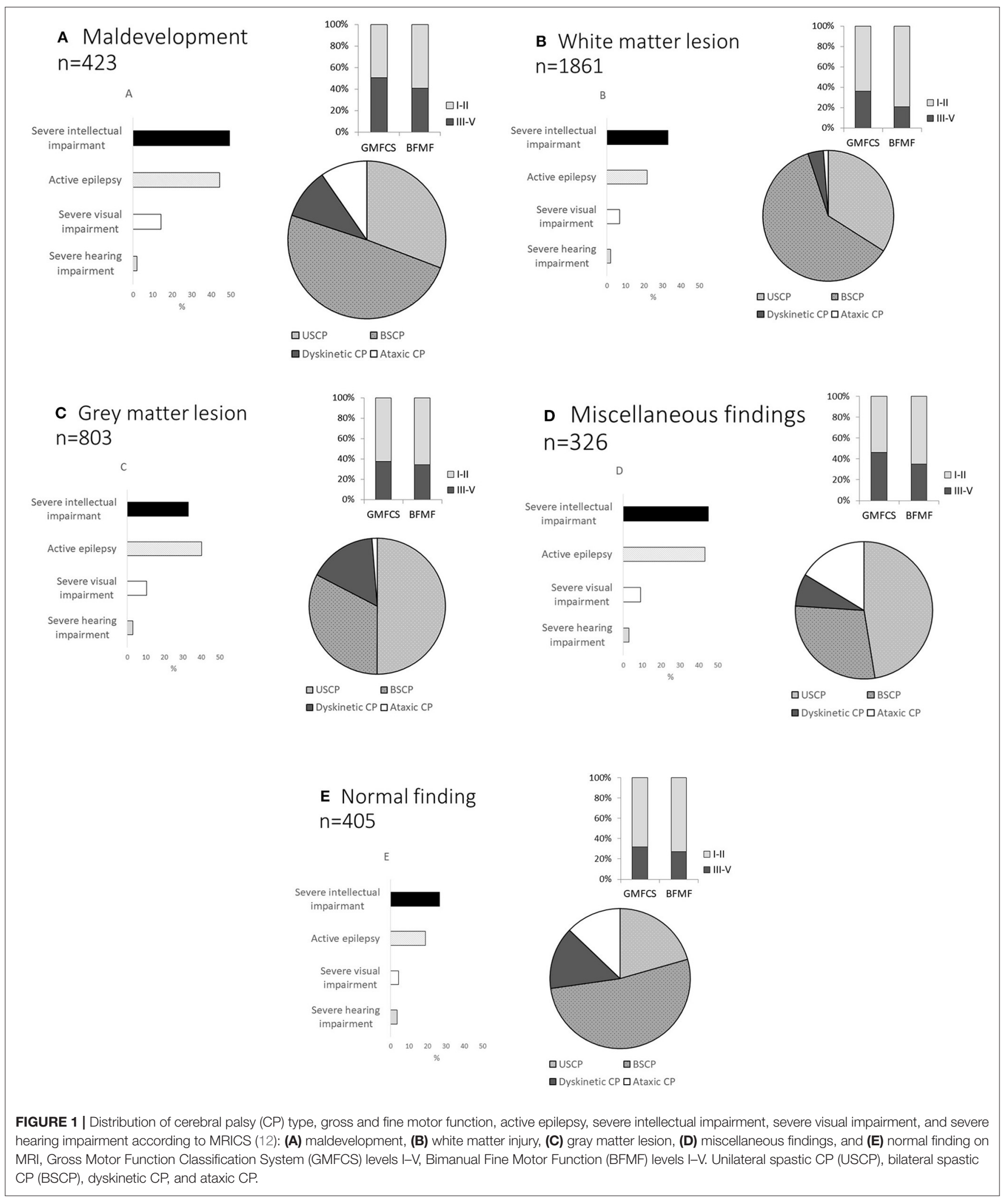




\section{Impairment index by neuroimaging pattern}

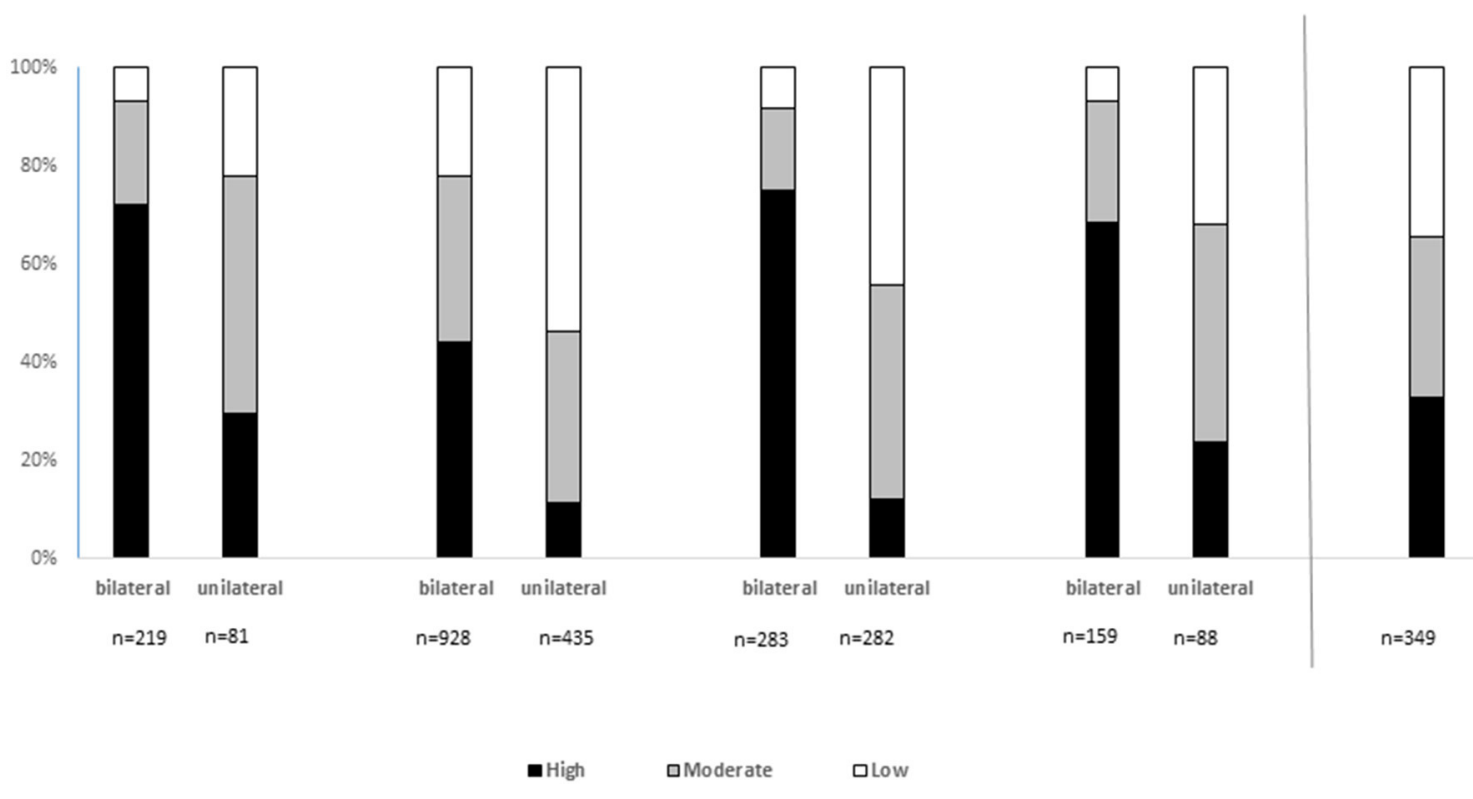

FIGURE 2 | Impairment index by neuroimaging pattern and by bilateral or unilateral findings in 2,824 children with cerebral palsy: Low impairment was defined as being able to walk (GMFCS I-II), IQ $\geq 70$, no visual impairment, no hearing impairment, and no epilepsy. High impairment was defined as inability to walk (GMFCS IV-V) and/or severe intellectual impairment $(\mathrm{IQ}<50)$, with or without one or more of the following impairments: severe visual impairment, severe hearing impairment, and active epilepsy. Moderate impairment included all other levels of impairment not defined as low or high.

visual impairment, severe hearing impairment, and/or active epilepsy OR walking with aids (GMFCS III), with an IQ $\geq 50$ with or without one or more of the following impairments: severe visual impairment, severe hearing impairment, and active epilepsy].

\section{Statistical Analysis}

Categorical variables were summarized as frequencies and percentages. To test for the association between imaging findings and clinical characteristics, chi-squared test or Fisher's exact test when appropriate was used. We also compared the distribution of CP types between children included in the study (with a postneonatal MRI) and the children excluded in the study (with no report of post-neonatal MRI) using the chi-square test.

The level of statistical significance was set at 0.05 .

\section{RESULTS}

There were 3,818 children with CP born 1999-2009 from 20 centers across Europe with an MRI performed in the postneonatal period, while 5,415 children had no MRI report: in 1,720 (45\%) children before 2 years of age (median age 12 months, interquartile range 8-16 months) and in 1,859 (49\%) children at 2 years of age or later, MRI was performed. Age was unknown in $239(6 \%)$ cases. The distribution of CP types was similar in the two groups (data not shown).
Of the 3,818 children, 1,320 (35.3\%) had USCP, $1,930(51.7 \%)$ had BSCP, 331 (8.9\%) had dyskinetic CP, and 154 (4.1\%) had ataxic $\mathrm{CP}$, while $\mathrm{CP}$ type was unknown in 83 children.

The most common findings were white matter injury (49.1\%) and gray matter injury (21.3\%). MRI findings differed between CP types $(p<0.001)$.

Clinical characteristics, such as CP type, gross and fine motor function, presence of epilepsy, and severe intellectual, visual, and hearing impairment, are shown by neuroimaging pattern in Figure 1.

Distribution of motor and accompanying impairment differed between neuroimaging patterns and whether lesions were uni- or bilateral. The impairment index was applied in 2,824 children, for whom sufficient information about impairments and MRI was registered (Figure 2).

\section{Neuroimaging Patterns Maldevelopments}

In 423 children, maldevelopment was found. This group had spastic CP in $77 \%$, and severe intellectual impairment in 55\%. Independent walkers (GMFCS I-II) comprised $47.4 \%$, while $52.5 \%$ relied on wheelchair ambulation. Severe visual impairment was found in $14.2 \%$, severe hearing impairment in $4.3 \%$ and active epilepsy in $46.2 \%$ (Figure 1A) Information on whether the lesion was uni- or bilateral was available in 338 children (Table 2). 
TABLE 2 | Comparison of subtype and associated impairments according to bilateral and unilateral lesion in children with predominant maldevelopments on brain MRI.

\begin{tabular}{|c|c|c|c|c|}
\hline \multirow[t]{2}{*}{ Impairment } & \multicolumn{3}{|c|}{$\begin{array}{l}\text { Localization of predominant } \\
\text { maldevelopments }\end{array}$} & \multirow[t]{2}{*}{$P$-value* } \\
\hline & $\begin{array}{c}\text { Bilateral } \\
N=244(\%)\end{array}$ & $\begin{array}{l}\text { Unilateral } \\
N=94(\%)\end{array}$ & $\begin{array}{c}\text { Unknown } \\
N=85\end{array}$ & \\
\hline CP type & & & & $<0.001$ \\
\hline Spastic bilateral & $149(63.1)$ & $16(17.2)$ & $35(45.4)$ & \\
\hline $\begin{array}{l}\text { Spastic } \\
\text { unilateral }\end{array}$ & 39 (16.5) & 65 (69.9) & $21(27.3)$ & \\
\hline Dyskinetic & 25 (10.6) & $6(6.4)$ & $11(14.3)$ & \\
\hline Ataxic & $23(9.7)$ & $6(6.4)$ & $10(13.0)$ & \\
\hline GMFCS III-V & 155 (64.6) & 17 (18.3) & $42(56.2)$ & $<0.001$ \\
\hline BFMF III-V & 124 (59.9) & $24(30.8)$ & $24(46.1)$ & $<0.001$ \\
\hline Epilepsy & & & & 0.40 \\
\hline Active & $114(48.5)$ & $37(40.7)$ & $37(45.7)$ & \\
\hline Not active & $15(6.4)$ & $8(8.8)$ & $3(3.7)$ & \\
\hline No epilepsy & $106(45.1)$ & $46(50.5)$ & $41(50.6)$ & \\
\hline $\begin{array}{l}\text { Severe intellectual } \\
\text { impairment }\end{array}$ & 147 (66.8) & $21(25.6)$ & $41(51.9)$ & $<0.001$ \\
\hline $\begin{array}{l}\text { Severe visual } \\
\text { impairment }\end{array}$ & $40(16.4)$ & $2(2.1)$ & $18(21.2)$ & $<0.001$ \\
\hline $\begin{array}{l}\text { Severe hearing } \\
\text { impairment }\end{array}$ & $14(5.7)$ & $4(4.3)$ & $0(-)$ & 0.59 \\
\hline
\end{tabular}

*The p-value corresponds to the comparison between bilateral and unilateral lesions. Unknown values were excluded from the comparison.

\section{White Matter Injury}

Of 1,861 children, $94 \%$ had spastic CP, bilateral in almost two thirds of these cases. A majority, 63\%, were independent walkers (GMFCS I-II). Only 23\% (404/1,774) had active epilepsy, $6.8 \%$ had severe visual impairment, and $1 \%$ severe hearing impairment, while severe intellectual impairment was found in 24\% (Figure 1B).

Information on whether the lesion was uni- or bilateral was available in 1,551 children. Children with bilateral white matter lesions mainly had BSCP, while in unilateral lesions, the majority had USCP. Severe intellectual impairment, severe visual and hearing impairments, and epilepsy were more common in children with bilateral than unilateral lesions (Table 3).

\section{Gray Matter Injury}

In this group of 803 children, bilateral lesions were found in 320 , and unilateral in 322 . The distribution as to uni- or bilateral was unknown in 150 cases (Figure 1C).

Uni- and bilateral gray matter lesions differed in outcome with a higher severity in terms of motor impairment and associated impairments for children with bilateral lesions (Table 4).

Children with bilateral gray matter lesions had the highest proportion of dyskinetic CP, 32\% (101/320).

In children with unilateral gray matter lesions, spastic CP dominated (97.5\%) and this was mainly unilateral.
TABLE 3 | Comparison of subtype and associated impairments according to bilateral and unilateral lesion in children with predominant white matter injury.

\begin{tabular}{|c|c|c|c|c|}
\hline \multirow[t]{2}{*}{ Impairment } & \multicolumn{3}{|c|}{$\begin{array}{l}\text { Localization of predominant white matter } \\
\text { lesions }\end{array}$} & \multirow[t]{2}{*}{$P$-value* } \\
\hline & $\begin{array}{c}\text { Bilateral } \\
N=1,058(\%)\end{array}$ & $\begin{array}{l}\text { Unilateral } \\
N=493(\%)\end{array}$ & $\begin{array}{l}\text { Unknown } \\
N=310\end{array}$ & \\
\hline CP type & & & & $<0.001$ \\
\hline Spastic bilateral & $850(81.7)$ & $86(17.6)$ & $182(59.7)$ & \\
\hline $\begin{array}{l}\text { Spastic } \\
\text { unilateral }\end{array}$ & $129(12.4)$ & 389 (79.5) & $106(34.7)$ & \\
\hline Dyskinetic & $48(4.6)$ & $8(1.6)$ & $14(4.6)$ & \\
\hline Ataxic & $13(1.2)$ & $6(1.2)$ & $3(1.0)$ & \\
\hline GMFCS III-V & $510(49.2)$ & $48(9.9)$ & 117 (38.9) & $<0.001$ \\
\hline BFMF III-V & $322(38.2)$ & $41(10.6)$ & 28 (25.9) & $<0.001$ \\
\hline Epilepsy & & & & $<0.001$ \\
\hline Active & $256(25.4)$ & $84(17.7)$ & 64 (21.9) & \\
\hline Not active & $74(7.3)$ & $23(4.8)$ & $22(7.5)$ & \\
\hline No epilepsy & 678 (67.3) & 367 (77.4) & 206 (70.5) & \\
\hline $\begin{array}{l}\text { Severe intellectual } \\
\text { impairment }\end{array}$ & 299 (32.0) & 45 (10.3) & $60(20.6)$ & $<0.001$ \\
\hline $\begin{array}{l}\text { Severe visual } \\
\text { impairment }\end{array}$ & $86(8.1)$ & $15(3.0)$ & $26(8.4)$ & $<0.001$ \\
\hline $\begin{array}{l}\text { Severe hearing } \\
\text { impairment }\end{array}$ & $29(2.7)$ & $4(0.8)$ & $2(0.6)$ & 0.01 \\
\hline
\end{tabular}

*The P-value corresponds to the comparison between bilateral and unilateral lesions. Unknown values were excluded from the comparison.

\section{Miscellaneous Findings}

Miscellaneous findings on MRI were found in 326 children, $74.5 \%$ had spastic $\mathrm{CP}, 10.7 \%$ dyskinetic, and $10 \%$ ataxic $\mathrm{CP}$. GMFCS levels were at III-V in $42.5 \%$. Active epilepsy and severe intellectual impairment were common, found in 40 and $49.7 \%$ respectively (Figure 1D). Information on whether the lesion was uni- or bilateral was available in 270 children (Table 5).

\section{Normal Finding}

Children with normal findings on post-neonatal MRI had a spastic CP in $70 \%(283 / 405)$, were able to walk independently (GMFCS I-II) in 68\%, had active epilepsy in 19\% (74/405), and had severe intellectual impairment in 26.5\% (94/405) (Figure 1E).

In summary, in children with maldevelopment, bilateral gray matter lesions, and miscellaneous findings on MRI, a more severe pattern of impairments was frequent, both regarding motor and associated impairments. In contrast, children with white matter injury and normal finding on MRI more often had a milder phenotype.

Children with bilateral white and gray matter lesions more frequently had a severe outcome than those with unilateral lesions.

The impairment index was applied in 2,824 children with sufficient information and revealed significant differences $(p<$ 0.001 , respectively) between uni- and bilateral MRI findings regardless of MRICS classification A through D, with a larger proportion of high impairment index in bilateral findings 
TABLE 4 | Comparison of subtype and associated impairments according to bilateral and unilateral lesion in children with predominant gray matter injury.

\begin{tabular}{|c|c|c|c|c|}
\hline \multirow[t]{2}{*}{ Impairment } & \multicolumn{3}{|c|}{$\begin{array}{l}\text { Localization of predominant gray matter } \\
\text { lesions }\end{array}$} & \multirow[t]{2}{*}{$P$-value* } \\
\hline & $\begin{array}{c}\text { Bilateral } \\
N=320(\%)\end{array}$ & $\begin{array}{l}\text { Unilateral } \\
N=322(\%)\end{array}$ & $\begin{array}{l}\text { Unknown } \\
N=161(\%)\end{array}$ & \\
\hline CP type & & & & $<0.001$ \\
\hline Spastic bilateral & $178(56.7)$ & $30(9.3)$ & $51(32.1)$ & \\
\hline $\begin{array}{l}\text { Spastic } \\
\text { unilateral }\end{array}$ & 32 (10.2) & $284(88.2)$ & $82(51.6)$ & \\
\hline Dyskinetic & $101(32.2)$ & $4(1.2)$ & $23(14.5)$ & \\
\hline Ataxic & $3(1.0)$ & $4(1.2)$ & $3(1.9)$ & \\
\hline GMFCS III-V & 232 (73.9) & $13(4.1)$ & $56(35.2)$ & $<0.001$ \\
\hline BFMF III-V & 202 (74.3) & 43 (16.6) & $26(54.2)$ & $<0.001$ \\
\hline Epilepsy & & & & $<0.001$ \\
\hline Active & $158(50.3)$ & $92(29.6)$ & $73(49.0)$ & \\
\hline Not active & $30(9.5)$ & $30(9.6)$ & $11(7.0)$ & \\
\hline No epilepsy & $126(40.1)$ & $189(60.8)$ & 69 (43.9) & \\
\hline $\begin{array}{l}\text { Severe intellectual } \\
\text { impairment }\end{array}$ & $179(62.8)$ & $30(10.6)$ & $56(36.6)$ & $<0.001$ \\
\hline $\begin{array}{l}\text { Severe visual } \\
\text { impairment }\end{array}$ & $48(15.0)$ & $7(2.2)$ & $29(18.0)$ & $<0.001$ \\
\hline $\begin{array}{l}\text { Severe hearing } \\
\text { impairment }\end{array}$ & $21(6.6)$ & $2(0.7)$ & $1(0.6)$ & $<0.001$ \\
\hline
\end{tabular}

*The P-value corresponds to the comparison between bilateral and unilateral lesions. Unknown values were excluded from the comparison.

(Figure 2). Children with white matter lesions (B) overall had the least severe impairment load.

\section{CP Types}

Spastic CP was the most frequent in all MRI patterns. Less common $\mathrm{CP}$ types, such as dyskinetic $\mathrm{CP}$ and ataxic $\mathrm{CP}$, were unevenly distributed. Most cases of dyskinetic CP were found in the group with bilateral gray matter injury.

Bilateral spastic CP was the most common CP subtype. Of the 1,118 children, severe motor and associated impairments were most frequent in those with maldevelopments or gray matter lesions (Table 6).

In unilateral spastic $\mathrm{CP}$, two different neuroimaging patterns dominated: white matter lesion (B) and gray matter lesion (middle cerebral artery infarction) (C), emanating from different timing of compromise. The two groups had a similar profile of impairment index but differed with regard to prevalence of accompanying impairments (Table 7). Children with unilateral spastic CP and gray matter lesion or maldevelopment had a higher proportion of severe intellectual impairment and epilepsy than those with white matter lesions.

\section{DISCUSSION}

Neuroimaging is an important tool in disclosing clues to the background of CP. More than $80 \%$ of brain imaging in $\mathrm{CP}$ is abnormal in most studies. To achieve a common language regarding neuroimaging findings, the SCPE has suggested a classification describing the different patterns of abnormality,
TABLE 5 | Comparison of subtype and associated impairments according to bilateral and unilateral lesion in children with miscellaneous findings on brain MRI.

\begin{tabular}{|c|c|c|c|c|}
\hline \multirow[t]{2}{*}{ Impairment } & \multicolumn{3}{|c|}{ Localization of miscellaneous findings } & \multirow[t]{2}{*}{$P$-value* } \\
\hline & $\begin{array}{c}\text { Bilateral } \\
N=175(\%)\end{array}$ & $\begin{array}{l}\text { Unilateral } \\
N=95(\%)\end{array}$ & $\begin{array}{l}\text { Unknown } \\
N=56\end{array}$ & \\
\hline CP type & & & & $<0.001$ \\
\hline Spastic bilateral & $104(61.5)$ & $23(24.5)$ & $23(47.9)$ & \\
\hline $\begin{array}{l}\text { Spastic } \\
\text { unilateral }\end{array}$ & $17(10.1)$ & 66 (70.2) & $10(20.8)$ & \\
\hline Dyskinetic & 27 (16.0) & $4(4.3)$ & $4(8.3)$ & \\
\hline Ataxic & 21 (12.4) & $1(1.1)$ & $10(20.8)$ & \\
\hline GMFCS III-V & $110(64.7)$ & $15(16.0)$ & 26 (49.1) & $<0.001$ \\
\hline BFMF III-V & 78 (52.7) & $21(25.0)$ & $16(42.1)$ & $<0.001$ \\
\hline Epilepsy & & & & 0.003 \\
\hline Active & 79 (48.2) & 30 (31.9) & 32 (29.6) & \\
\hline Not active & $20(12.2)$ & $6(6.4)$ & $6(11.1)$ & \\
\hline No epilepsy & 65 (39.6) & $58(61.7)$ & 32 (59.3) & \\
\hline $\begin{array}{l}\text { Severe intellectual } \\
\text { impairment }\end{array}$ & 101 (63.5) & $21(23.6)$ & $25(52.1)$ & $<0.001$ \\
\hline $\begin{array}{l}\text { Severe visual } \\
\text { impairment }\end{array}$ & $24(13.7)$ & $0(-)$ & $6(10.7)$ & $<0.001$ \\
\hline $\begin{array}{l}\text { Severe hearing } \\
\text { impairment }\end{array}$ & $9(5.1)$ & 3 (3.2) & $1(1.8)$ & 0.55 \\
\hline
\end{tabular}

*The $p$-value corresponds to the comparison between bilateral and unilateral lesions. Unknown values were excluded from the comparison.

based on the timing of insult to the brain (12). This gives a possibility to investigate structure-function relationships and may help in predicting future impairments and increase the possibilities of prevention and treatment. Earlier studies have suggested a relationship between lesions occurring late in gestation and impaired speech and communication (19), and outcome of gross and fine motor function are also found to be related to timing of the lesion $(4,20,21)$. Extent and topography of the lesions also play a role. Whether lesions affect cerebral hemispheres uni- or bilaterally is crucial for functional outcome. Following early brain lesions that are unilateral, the brain can refer to homotopic areas of the healthy hemisphere. This potential for reorganization is unique to the young brain. With respect to motor function, ipsilateral motor tracts can be recruited, but with relevant functionality only in earlier brain lesions, e.g., before the end of the third trimester of pregnancy or equivalent preterm age (22). Language can be reorganized to the right after early left hemispheric lesions up to early childhood age, as the representation of the language network is initially bilateral, whereas the young brain is more sensitive and vulnerable to lesions when these are bilateral and interfere with early network building $(4,23)$.

This study aimed to describe functional profiles by the neuroimaging patterns of the MRICS, using the large populationbased database of the SCPE (11). A previous report from this database stated that the neuroimaging findings were mainly lesional, while maldevelopment, miscellaneous, and normal findings constituted smaller groups (13) and studies from national registers find similar results $(24,25)$. The present study 
TABLE 6 | Comparison of associated impairments according to main lesion in children with bilateral spastic CP.

\begin{tabular}{|c|c|c|c|c|c|c|}
\hline \multirow[t]{3}{*}{ Impairment } & \multicolumn{5}{|c|}{ MRI finding } & \multirow[t]{3}{*}{$P$-value } \\
\hline & A & B & C & D & $\mathbf{E}$ & \\
\hline & $N=200$ & $N=1,118$ & $N=259$ & $N=150$ & $N=203$ & \\
\hline GMFCS III-V & $157(80.1)$ & $594(54.0)$ & $189(74.4)$ & $96(66.7)$ & $73(36.9)$ & $<0.001$ \\
\hline BFMF III-V & $118(72.8)$ & $319(39.2)$ & $137(74.5)$ & $69(59.0)$ & $31(23.8)$ & $<0.001$ \\
\hline Epilepsy & & & & & & $<0.001$ \\
\hline Active & $109(56.2)$ & $282(26.4)$ & $143(56.3)$ & $65(46.1)$ & $35(18.0)$ & \\
\hline Not active & $14(7.2)$ & $76(7.1)$ & $25(9.8)$ & $17(12.1)$ & $11(5.7)$ & \\
\hline No epilepsy & $571(36.6)$ & 708 (66.4) & $86(33.9)$ & $59(41.8)$ & 148 (76.3) & \\
\hline Severe intellectual impairment & $135(73.0)$ & 312 (31.3) & 166 (70.0) & $86(64.2)$ & 53 (29.3) & $<0.001$ \\
\hline Severe visual impairment & $45(22.5)$ & $94(8.4)$ & $59(22.8)$ & $17(11.3)$ & $11(5.4)$ & $<0.001$ \\
\hline Severe hearing impairment & $10(5.0)$ & $24(2.1)$ & 12 (4.6) & $7(4.7)$ & $5(2.5)$ & 0.05 \\
\hline
\end{tabular}

TABLE 7 | Comparison of associated impairments according to main lesion in children with unilateral spastic CP.

\begin{tabular}{|c|c|c|c|c|c|c|}
\hline \multirow[t]{3}{*}{ Impairment } & \multicolumn{5}{|c|}{ MRI finding } & \multirow[t]{3}{*}{$P$-value } \\
\hline & A & B & C & D & $\mathbf{E}$ & \\
\hline & $N=125$ & $N=624$ & $N=398$ & $N=93$ & $N=80$ & \\
\hline GMFCS III-V & $8(6.4)$ & $15(2.4)$ & $7(1.8)$ & $7(7.5)$ & $0(-)$ & 0.002 \\
\hline BFMF III-V & $16(15.4)$ & $30(6.9)$ & $43(15.6)$ & $9(11.0)$ & $2(3.7)$ & 0.001 \\
\hline Epilepsy & & & & & & $<0.001$ \\
\hline Active & 43 (35.2) & $90(14.9)$ & $126(32.6)$ & $28(30.1)$ & $7(8.9)$ & \\
\hline Not active & $10(8.2)$ & $27(4.5)$ & $32(8.3)$ & $7(7.5)$ & $6(7.6)$ & \\
\hline No epilepsy & 69 (56.6) & $485(80.6)$ & $228(59.1)$ & $58(62.4)$ & $66(83.5)$ & \\
\hline Severe intellectual impairment & $19(17.8)$ & $38(6.7)$ & $40(11.1)$ & $15(16.8)$ & $3(4.3)$ & $<0.001$ \\
\hline Severe visual impairment & $3(2.4)$ & $18(2.9)$ & $9(2.3)$ & $2(2.1)$ & $0(-)$ & 0.62 \\
\hline Severe hearing impairment & $6(4.8)$ & $7(1.1)$ & $3(0.7)$ & $1(1.1)$ & $1(1.2)$ & 0.01 \\
\hline
\end{tabular}

shows that the impairment load in terms of occurrence of severe intellectual, visual, and hearing impairment and epilepsy, as well as in the distribution of gross and fine motor impairment, differs between neuroimaging patterns. Moreover, the severity of motor function and occurrence of associated impairments differs between children with unilateral and bilateral lesions, the latter associated with a more severe phenotype, in all neuroimaging patterns. As discussed above, homotopic areas in an unaffected hemisphere offer the possibility to reorganize and compensate for function, whereas vulnerability of the young brain to bilateral lesions is probably higher than in later age (4). This finding was supported when applying the impairment index (18), showing a significant difference in impairment load between uni- and bilateral maldevelopments or lesions, regardless of timing of event during gestation. It is noteworthy that unilateral white matter injuries (representing mostly periventricular hemorrhagic infarctions of preterm children, former IVH grade IV) present with the least impairment load, even less than unilateral gray matter injuries (e.g., arterial infarctions). We consider this an important aspect in the early counseling of the parents of a preterm child.

An increasing number of associated impairments have been recognized in children with $\mathrm{CP}$. Recent contributions are neuropsychiatric disorders, reported to be associated with male sex, epilepsy, and intellectual disability in European children with CP (26). Other studies have pointed toward an association with white matter injuries $(27,28)$. Early insults to the brain may predict both attention and executive functioning $(29,30)$. Disruption of structural brain connectivity has been found, not only in the sensorimotor system but also in posterior brain regions, associated with intellectual impairment in individuals with dyskinetic CP (31). Thus, many factors affect the occurrence of impairment in children with early insult to the brain, and much is still unknown.

Limitations to this study must be recognized. The data came from the largest population-based database on children with CP worldwide. However, not all children had been subject to MRI. Also, there were missing data of whether the neuroimaging findings were uni- or bilateral. Information about intellectual impairment was in some cases based on estimation, often due to difficulties performing formal tests in severe cases.

However, the existing data provide a large basis to clarify structure-function relationships in the heterogeneous population of children with $\mathrm{CP}$, illustrating that the proportion of severe impairments is clearly larger in children with bilateral lesions, consistent with previous findings (4). Moreover, the classification of MRI reports and scans was done and 
validated in a structured and uniform way, strengthening data quality.

Further insights in the association between early brain compromise and clinical outcome in $\mathrm{CP}$ may be gained using a harmonized classification of neuroimaging findings such as the MRICS as a basis for research. As suggested earlier (12), additional information with regard to exact topography and extent of the brain lesions must be taken into account $(32,33)$. Such insights must be combined with additional knowledge about the child, for example regarding cognitive functioning (34).

We conclude that the distribution of motor and associated impairments differed between neuroimaging patterns in children with CP. A consistent finding was that bilateral lesions or maldevelopment more often gave a severe phenotype. This information may support individual counseling and planning of support of the child with CP.

\section{DATA AVAILABILITY STATEMENT}

The datasets presented in this article are not readily available because the dataset is derived from the Central Database of JRCSCPE, where requests should be directed. Requests to access the datasets should be directed to JRC-SCPE@ec.europa.eu.

\section{AUTHOR CONTRIBUTIONS}

$\mathrm{KH}$ drafted and revised the manuscript. VH, ES, JD, AP, and IK-M contributed to and critically revised several versions of the manuscript. The SCPE Collaboration contributed to and critically revised a final manuscript together with $\mathrm{KH}, \mathrm{VH}, \mathrm{ES}$, JD,

\section{REFERENCES}

1. Rosenbaum P, Paneth N, Leviton A, Goldstein M, Bax M, Damiano D, et al. A report: the definition and classification of cerebral palsy April 2006. Dev Med Child Neurol Suppl. (2007). 109:8-14.

2. Ashwal S, Russman BS, Blasco PA, Sandler A, Shevell M, et al. Practice parameter: diagnostic assessment of the child with cerebral palsy: report of the Quality Standards Subcommittee of the American Academy of Neurology and the Practice Committee of the Child Neurology Society. Neurology. (2004). 62:851-63. doi: 10.1212/01.wnl.0000117981.35364.1b

3. Novak I, Morgan C, Adde L, Blackman J, Boyd RN, Brunstrom-Hernandez J, et al. Early, accurate diagnosis and early intervention in cerebral palsy: advances in diagnosis and treatment. JAMA Pediatr. (2017) 171:897907. doi: 10.1001/jamapediatrics.2017.1689

4. Krägeloh-Mann I, Lidzba K, Pavlova MA, Wilke M, Staudt M. Plasticity during early brain development is determined by ontogenetic potential. Neuropediatrics. (2017). 48:66-71. doi: 10.1055/s-0037-1599234

5. Krägeloh-Mann I. Imaging of early brain injury and cortical plasticity. Exp Neurol. (2004). 190(Suppl. 1):S84-90. doi: 10.1016/j.expneurol.2004.05.037

6. Krägeloh-Mann I, Horber V. The role of magnetic resonance imaging in elucidating the pathogenesis of cerebral palsy: a systematic review. Dev Med Child Neurol. (2007). 49:144-51. doi: 10.1111/j.1469-8749.2007.00144.x

7. Korzeniewski SJ, Birbeck G, DeLano MC, Potchen MJ, Paneth N. A systematic review of neuroimaging for cerebral palsy. J Child Neurol. (2008). 23:21627. doi: $10.1177 / 0883073807307983$

8. Benini R, Dagenais L, Shevell MI; Registre de la Paralysie Cérébrale au Québec (Quebec Cerebral Palsy Registry) Consortium. Normal imaging in
AP, and IK-M. All authors contributed to the article and approved the submitted version.

\section{SCPE COLLABORATION (REGISTRY LEADERS)}

Elodie Sellier (RHEOP, Grenoble, France), Catherine Arnaud (RHE31, Toulouse, France), Oliver Perra (NICPR, Belfast, UK), Kate Himmelmann (Gothenburg, Sweden), Owen Hensey (Dublin, Ireland), Karen Horridge (Sunderland, UK), Mary Jane Platt (Norwich, UK), Gija Rackauskaite (Copenhagen, Denmark), Marco Marcelli (Viterbo, Italy), Guro L. Andersen (Tonsberg, Norway), Javier De la Cruz (Madrid, Spain), David Neubauer (Ljubljana, Slovenia), Daniel Virella (Lisbon, Portugal), Antigone Papavasiliou (Athens, Greece), Andra Greitane (Riga, Latvia), Katalin Hollody (Pecs, Hungary), Solveig Sigurdardottir (Kopavogur, Iceland), Fiona Zeiner (Innsbruck, Austria), Vlatka Mejaski-Bosnjak (Zagreb, Croatia), Els Ortibus (Leuven, Belgium), Ingeborg Krägeloh-Mann (Tübingen, Germany), Stephen Attard (Malta), and Ecaterina Bufteac (Chisinau, Moldova).

\section{ACKNOWLEDGMENTS}

This study, based on data from 20 SCPE registers across Europe for birth years 1999-2009, was possible thanks to the data collection and management performed by the JRCSCPE Central Registry, part of the EU Platform for Rare Diseases registration. patients with cerebral palsy: what does it tell us? J Pediatr. (2013). 162:36974.e1. doi: 10.1016/j.jpeds.2012.07.044

9. Numata Y, Onuma A, Kobayashi Y, Sato-Shirai I, Tanaka S, Kobayashi S, et al. Brain magnetic resonance imaging and motor and intellectual functioning in 86 patients born at term with spastic diplegia. Dev Med Child Neurol. (2013). 55:167-72. doi: 10.1111/dmcn.12013

10. Reid SM, Dagia CD, Ditchfield MR, Carlin JB, Meehan EM, Reddihough DS. An Australian population study of factors associated with MRI patterns in cerebral palsy. Dev Med Child Neurol. (2014). 56:17884. doi: $10.1111 / \mathrm{dmcn} .12331$

11. Cans C. Surveillance of cerebral palsy in Europe: a collaboration of cerebral palsy surveys and registers. Surveillance of Cerebral Palsy in Europe (SCPE). Dev Med Child Neurol. (2000) 42:816-24. doi: 10.1017/s0012162200001511

12. Himmelmann K, Horber V, De La Cruz J, Horridge K, Mejaski-Bosnjak V, Hollody K, et al. MRI classification system (MRICS) for children with cerebral palsy: development, reliability, and recommendations. Dev Med Child Neurol. (2017). 59:57-64. doi: 10.1111/dmcn.13166

13. Horber V, Sellier E, Horridge K, Rackauskaite G, Andersen GL, Virella D. The origin of the cerebral palsies: contribution of population-based neuroimaging data. Neuropediatrics. (2020) 51:113-9. doi: 10.1055/s-0039-3402007

14. Platt MJ, Krageloh-Mann I, Cans C. Surveillance of cerebral palsy in Europe: reference and training manual. Med Educ. (2009). 43:4956. doi: 10.1111/j.1365-2923.2009.03351.x

15. Palisano R, Rosenbaum P, Walter S, Russell D, Wood E, Galuppi B. Development and reliability of a system to classify gross motor function in children with cerebral palsy. Dev Med Child Neurol. (1997). 39:21423. doi: 10.1111/j.1469-8749.1997.tb07414.x 
16. Beckung E, Hagberg G. Neuroimpairments, activity limitations, and participation restrictions in children with cerebral palsy. Dev Med Child Neurol. (2002). 44:309-16. doi: 10.1017/s0012162201002134

17. Elvrum AG, Beckung E, Sæther R, Lydersen S, Vik T, Himmelmann K. Bimanual capacity of children with cerebral palsy: intra- and interrater reliability of a revised edition of the bimanual fine motor function classification. Phys Occup Ther Pediatr. (2017). 37:239-51. doi: 10.1080/01942638.2016.1185507

18. Horber V, Fares A, Platt MJ, Arnaud C, Krägeloh-Mann I, Sellier E. Severity of cerebral palsy-the impact of associated impairments. Neuropediatrics. (2020). 51:120-8. doi: 10.1055/s-0040-1701669

19. Himmelmann K, Lindh K, Hidecker MJ. Communication ability in cerebral palsy: a study from the CP register of western Sweden. Eur J Paediatr Neurol. (2013). 17:568-74. doi: 10.1016/j.ejpn.2013.04.005

20. Himmelmann K, Uvebrant P. Function and neuroimaging in cerebral palsy: a population-based study. Dev Med Child Neurol. (2011). 53:51621. doi: 10.1111/j.1469-8749.2011.03932.x

21. Klingels K, Jaspers E, Staudt M, Guzzetta A, Mailleux L, Ortibus E, et al. Do mirror movements relate to hand function and timing of the brain lesion in children with unilateral cerebral palsy? Dev Med Child Neurol. (2016) 58:735-42. doi: 10.1111/dmcn. 12977

22. Staudt M, Gerloff C, Grodd W, Holthausen H, Niemann G, Krägeloh-Mann I. Reorganization in congenital hemiparesis acquired at different gestational ages. Ann Neurol. (2004) 56:854-63. doi: 10.1002/ana.20297

23. Pavlova MA, Krägeloh-Mann I. Limitations on the developing preterm brain: impact of periventricular white matter lesions on brain connectivity and cognition. Brain. (2013) 136 (Pt 4):998-1011. doi: 10.1093/brain/aws334

24. Nagy E, Herbert Z, Péter I, Csorba E, Skobrák A, Farkas N, et al. The usefulness of MRI Classification System (MRICS) in a cerebral palsy cohort. Acta Paediatr. (2020) 109:2783-8. doi: 10.1111/apa.15280

25. Delin S, Bošnjak Nad K, Martinec S, Cokolić Petrović D, Šimic Klarić A, Mejaški Bošnjak V. Prognostic value of cranial ultrasonography in comparison with magnetic resonance imaging in children with cerebral palsy: a population-based study. Acta Clin Croat. (2020) 59:260-9. doi: 10.20471/acc.2020.59.02.09

26. Delobel-Ayoub M, Klapouszczak D, van Bakel MME, Horridge K, Sigurdardottir S, Himmelmann K, et al. Prevalence and characteristics of autism spectrum disorders in children with cerebral palsy. Dev Med Child Neurol. (2017) 59:738-42. doi: 10.1111/dmcn.13436

27. Woodward LJ, Clark CA, Bora S, Inder TE. Neonatal white matter abnormalities an important predictor of neurocognitive outcome for very preterm children. PLoS ONE. (2012). 7:e51879. doi: 10.1371/journal.pone.0051879

28. Cainelli E, Arrigoni F, Vedovelli L. White matter injury and neurodevelopmental disabilities: a cross-disease (dis)connection. Prog Neurobiol. (2020). 193:101845. doi: 10.1016/j.pneurobio.2020. 101845

29. Spencer-Smith M, Anderson P, Jacobs R, Coleman L, Long B, Anderson V. Does timing of brain lesion have an impact on children's attention? Dev Neuropsychol. (2011). 36:353-66. doi: 10.1080/87565641.2010. 549983

30. Bosenbark DD, Krivitzky L, Ichord R, Vossough A, Bhatia A, Jastrzab LE, et al. Clinical predictors of attention and executive functioning outcomes in children after perinatal arterial ischemic stroke. Pediatr Neurol. (2017). 69:79-86. doi: 10.1016/j.pediatrneurol.2017.01.014

31. Ballester-Plané J, Schmidt R, Laporta-Hoyos O, Junqué C, Vázquez É, Delgado I, et al. Whole-brain structural connectivity in dyskinetic cerebral palsy and its association with motor and cognitive function. Hum Brain Mapp. (2017). 38:4594-612. doi: 10.1002/hbm.23686

32. Faria AV, Hoon A, Stashinko E, Li X, Jiang H, Mashayekh A, et al. Quantitative analysis of brain pathology based on MRI and brain atlases-applications for cerebral palsy. Neuroimage. (2011) 54:1854-61. doi: 10.1016/j.neuroimage.2010.09.061

33. Fiori S, Cioni G, Klingels K, Ortibus E, Van Gestel L, Rose S, et al. Reliability of a novel, semi-quantitative scale for classification of structural brain magnetic resonance imaging in children with cerebral palsy. Dev Med Child Neurol. (2014). 56:839-45. doi: 10.1111/dmcn.12457

34. Stadskleiv K. Cognitive functioning in children with cerebral palsy. Dev Med Child Neurol. (2020) 62:283-9. doi: 10.1111/dmcn.14463

Conflict of Interest: The authors declare that the research was conducted in the absence of any commercial or financial relationships that could be construed as a potential conflict of interest.

Copyright (C) 2021 Himmelmann, Horber, Sellier, De la Cruz, Papavasiliou, KrägelohMann and the Surveillance of Cerebral Palsy in Europe (SCPE) Collaboration. This is an open-access article distributed under the terms of the Creative Commons Attribution License (CC BY). The use, distribution or reproduction in other forums is permitted, provided the original author(s) and the copyright owner(s) are credited and that the original publication in this journal is cited, in accordance with accepted academic practice. No use, distribution or reproduction is permitted which does not comply with these terms. 